\title{
Sağlık Hizmetlerinde Ekonomik Değerlendirme Yöntemleri
}

\section{Economic Evaluation Methods in Health Care}

\author{
İbrahim DOĞAN ${ }^{1}$, Ali ÜNAL ${ }^{2}$, Muhammet ÇANKAYA ${ }^{3}$
}

Article Info

Article History:

Date Submitted: 02.08.2019

Date Accepted: 26.08.2019

Jel Classification

I10, I15, H51

Keywords:

Health, Economic

Evaluation, Cost

\begin{abstract}
Competition has gained momentum in many sectors with the effect of globalization and has affected health services. Costs increase with the emergence of new and more comprehensive treatment methods and technological developments in health. Cost analysis has gained importance for health service providers to ensure their financial sustainability with changing conditions.

Economic evaluation methods are tools that make rational decisions on the allocation of limited resources. It makes cost and benefit comparisons of new treatments, drugs and medical supplies, and helps policy makers and decisionmakers choose the most effective alternative. Due to the limited resources allocated to health services, it is considered necessary to use economic evaluation methods in many decision-making processes. In this study, economic evaluation methods used in previous studies are examined. As a result of the research, it has been determined that cost effectiveness method is used frequently, service costs are examined more in cost accounts and studies on disease cost are limited. In particular, studies that deal with the social cost of the disease are insufficient.
\end{abstract}

\section{Özet}

Küreselleşmenin etkisi ile birlikte birçok sektörde hız kazanan rekabet, sağlık hizmetlerini de etkilemiştir. Sağlıkta yeni ve daha kapsamlı tedavi yöntemlerinin ortaya çıkması ve teknolojik gelişmeler ile birlikte maliyetler artmaktadır. Değişen koşullar ile birlikte sağlık hizmeti sunucularının finansal sürdürülebilirliklerini sağlayabilmeleri için maliyet analizleri önem kazanmıştır.

\footnotetext{
${ }^{1}$ Hitit Üniversitesi Sağlık Bilimleri Fakültesi Sağık Yönetimi Bölümü, doganibrahim@hitit.edu.tr

2 Hitit Üniversitesi Sağlık Bilimleri Fakültesi Sağlık Yönetimi Bölümü, aliunal@hitit.edu.tr

${ }^{3}$ Hitit Üniversitesi Sağlık Bilimleri Fakültesi Sağlık Yönetimi Bölümü, $\underline{\text { muhammetcankaya@ @itit.edu.tr }}$
} 
Ekonomik değerlendirme yöntemleri sınırlı kaynakların tahsisinde rasyonel kararlar sağlayan araçlardır. Yeni tedaviler, ilaçlar ve tıbbi malzemeler hakkında maliyet ve fayda karşılaştırmaları yapmakta ve politika yapıcı ve karar vericilere en etkili alternatifin seçiminde yardımcı olmaktadır. Sağlık hizmetlerine ayrılan kaynakların kısıtlı olması sebebi ile birçok karar verme sürecinde ekonomik değerlendirme yöntemlerinin kullanımının gerekli olduğu düşünülmektedir. Bu çalışmada daha önceki çalışmalarda kullanılan ekonomik değerlendirme yöntemleri incelenmiştir. Araştırma sonucunda maliyet etkililik yönteminin sıkça kullanıldığı, maliyet hesaplarında hizmet maliyetlerinin daha çok incelendiği, hastalık maliyetine yönelik çalışmaların sınırlı olduğu tespit edilmiştir. Özellikle hastalık maliyetinde hastalığın sosyal maliyetinin ele alındığı çalışmalar yetersiz kalmaktadır.

\section{Giriş}

Sağlık ve sağlık hizmetleri insan ve toplum yaşamında önemli bir yere sahiptir. Sağlık hizmetleri ikamesi olmayan, ertelenemeyen, çıktısı paraya çevrilemeyen özelliktedir (Tengilimoğlu vd. 2018). Bunların bir sonucu olarak birçok ülke gayri safi yurtiçi hasılasının (GSYİH) giderek artan bir oranını sağlık hizmetlerine ayırmaktadır. Sağlık teknolojisindeki hızlı değişim, nüfus artışı, yaşıı nüfus artışı, farklı alanlarda yükseköğrenim görmüş uzmanlara ihtiyaç duyulması, daha iyi hizmet talebinde bulunulması gibi etmenler sebebiyle sağlık harcamaları artmaktadır (Ağırbaş, 1999). Artan sağlık harcamaları ile birlikte dünyadaki mevcut sağlık bakım sistemlerinin sürdürülebilirliğine yönelik endişeler artmaktadır (Rudmik ve Drummond, 2013). Türkiye'de kişi başına düşen sağlık harcaması 2017 yılında 824 dolar (OECD, 2018a) ve sağlık harcamalarının GSYİH içindeki oranı 4.2 olarak görülmektedir (OECD, 2018b). Tablo 1 incelendiğinde Türkiye'nin nominal sağlık harcamasının yıllara göre artış gösterdiği görülmektedir.

Tablo 1. Sağlık Harcamaları ile İlgili Göstergeler 2010-2017

\begin{tabular}{lcccccccc}
\hline & $\mathbf{2 0 1 0}$ & $\mathbf{2 0 1 1}$ & $\mathbf{2 0 1 2}$ & $\mathbf{2 0 1 3}$ & $\mathbf{2 0 1 4}$ & $\mathbf{2 0 1 5}$ & $\mathbf{2 0 1 6}$ & $\mathbf{2 0 1 7}$ \\
\hline $\begin{array}{l}\text { Toplam Sağlık } \\
\begin{array}{l}\text { Harcaması } \\
\text { (Milyon TL) }\end{array}\end{array}$ & 61.678 & 68.607 & 74.189 & 84.390 & 94.750 & 104.568 & 119.756 & 140.647 \\
\hline $\begin{array}{l}\text { Toplam sağlık } \\
\text { harcamasının } \\
\text { gayri safi } \\
\text { yurtiçi hasılaya } \\
\text { oranı (\%) }\end{array}$ & 5,3 & 4,9 & 4,7 & 4,7 & 4,6 & 4,5 & 4,6 & 4,5 \\
\hline
\end{tabular}

Kaynak: TÜİK, 2019. 
Artan sağlık harcamaları ile birlikte sağlık hizmetleri için ayrılan bütçenin kısıtlı olması, etkin sonuca ulaşmada sunulacak hizmetler arasında bir karar verme sürecini ortaya çıkarmıştır (Cunningham, 2001). Ekonomik değerlendirme olarak adlandırılan bu karar verme süreci alternatif eylemlerin maliyetlerinin ve sonuçlarının karşılaştırmalı analizidir. Tüm sağlık kaynaklarının kıt olduğu temel anlayışı ile kaynakların tahsisine yönelik en uygun maliyetli seçeneği belirlemek için alternatifleri değerlendirmekle ilgilidir (Rudmik ve Drummond, 2013). Türkiye'de ekonomik değerlendirme çalışmaları genellikle sağlı teknolojisini değerlendirmede (STD) kullanılmaktadır. STD, sağlık teknolojilerinin veya müdahalenin özelliklerinin ve etkilerinin sistematik olarak değerlendirilmesidir. Bu değerlendirmeler sağlık teknolojileri veya müdahalelerinin hem istenen hem de istenmeyen sonuçlarının tümünü kapsamaktadır (WHO, 2019a).

\section{Ekonomik Değerlendirme}

Ekonomik değerlendirmenin temeli alternatiflerin maliyetlerinin ve sonuçlarının karşılaştırılıp değerlendirilmesidir. Grafik 1'de ekonomik değerlendirmenin temel bileşenleri örnek bir ilaç tedavisi üzerinden gösterilmiştir.

Grafik 1. Ekonomik Değerlendirmenin Temel Bileşenleri

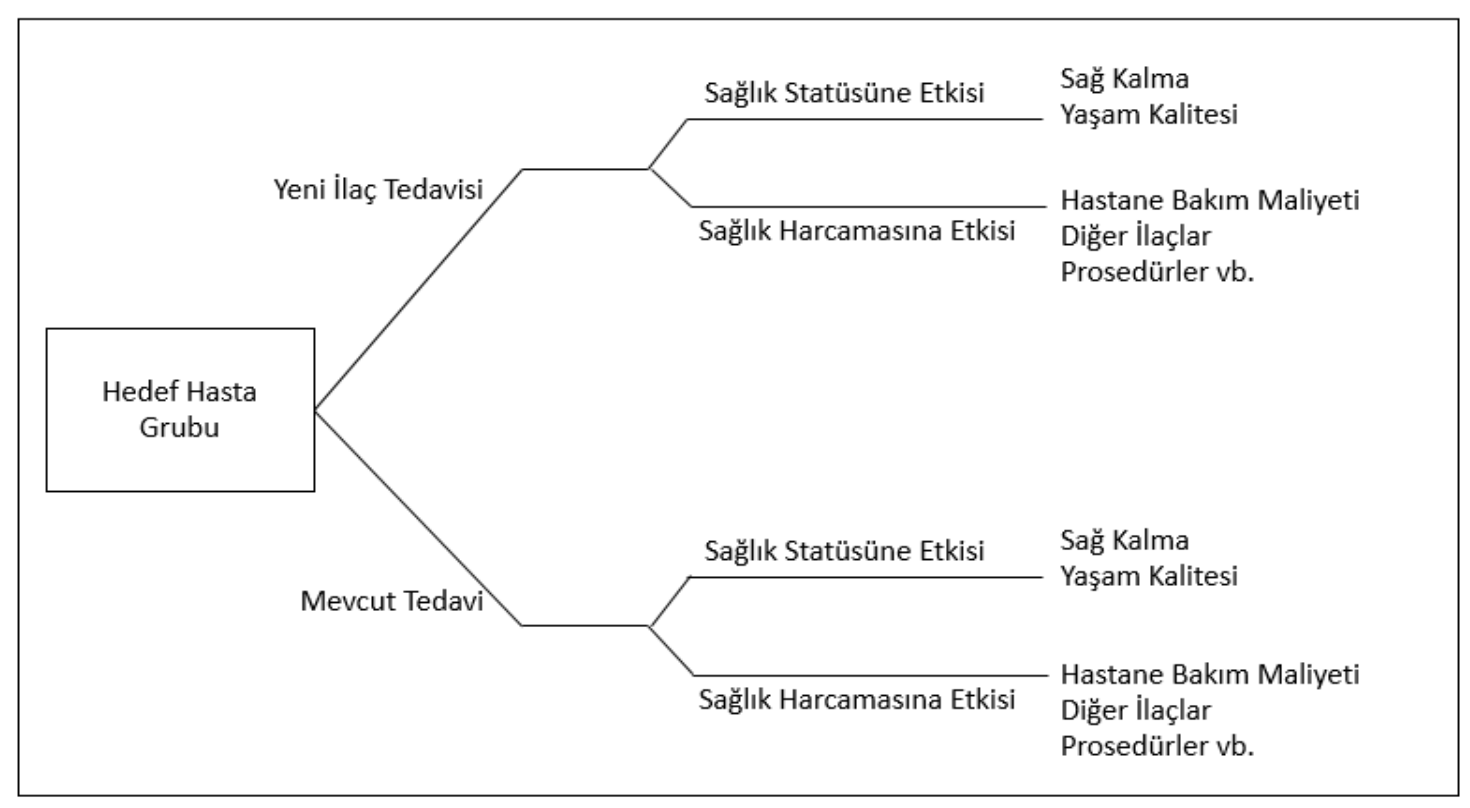

Kaynak: Drummond vd, 2006. 
Grafik 1 incelendiğinde hedef hasta grubuna uygulanan mevcut tedavinin sağlik statüsüne ve sağlık harcamasına (maliyet) etkisi olduğu görülmektedir. Alternatif yeni ilaç tedavisinin de aynı şekilde sağlık statüsüne ve sağlık harcamasına bir etkisi olduğu görülmektedir. Ekonomik değerlendirme kapsamında alternatif yeni ilaç tedavisinin sağlık statüsüne ve sağlık harcamasına olan etkisi bakımından daha rasyonel bir karar olup olmayacağı incelenir. Bu kapsamda sağlık ekonomisinde ekonomik değerlendirme yöntemleri bir karar verme aracı olarak kullanılmaktadır.

\section{Ekonomik Değerlendirme Yöntemleri}

Sağlık ekonomisinde ekonomik değerlendirme amacıyla iki ya da daha fazla sağlık müdahalesinin maliyetler ve etkiler açısından karşılaştırılması için birçok analitik teknik kullanılır. Bu teknikler sağlık sistemlerinde karar vericilerin kaynakları daha verimli bir şekilde tahsis etmelerini ve hasta için en iyi sonuç veya çıktıyı en düşük maliyet ile elde edilmesini sağlar. Temel olarak üç ekonomik değerlendirme yöntemi vardır: maliyet-etkililik analizi, maliyet-fayda analizi, maliyet-değer analizi. Bu yöntemlere bazı yazarlar maliyetminimizasyon analizini eklemektedirler. Bu teknikler arasındaki fark, sonuçlar veya çıktıların ölçülme şeklidir (Višnjić vd. 2011).

\subsection{Maliyet Minimizasyon (Cost - Minimalization) Analizi (MMA)}

Maliyet minimizasyonu analizi, iki müdahale arasındaki maliyetin basit bir şekilde karşılaştırılmasını yapmaktadır. MMA, yalnızca iki müdahale arasındaki sonuçların aynı olduğu varsayıldığında kullanılmalıdır. Amaç, alternatifler arasındaki en düşük maliyetli olanı belirlemektir. Karşılaştırılacak alternatiflerin sonuçlarının denkliği şeffaf ve anlaşılabilir bir şekilde sunulmalıdır (Walter ve Zehetmayr; Rudmik ve Drummond, 2013). Sağlık sektöründe MMA’nın kullanılabileceği durumlar sınırlıdır çünkü alternatifler elde edilen sonuçların aynı olma olasılı̆̆ı oldukça azdır (Ağırbaş, 1999). Örnek olarak fitık ameliyatında evde bakım ile hastanede yatma kıyaslaması verilebilir (Çelik, 2013). Uzmanların çoğu, bu basit analizin ekonomik değerlendirme başlı̆̆ı altına alınmaması gerektiğine inanmaktadır (Rudmik ve Drummond, 2013).

\subsection{Maliyet Fayda (Cost - Benefit) Analizi (MFA)}

Maliyet fayda analizi, ekonomi biliminin ekonomik değerlendirme kullandiğ yöntemlerden biridir (Ağırbaş, 2014). MFA, ekonomik değerlendirme yöntemleri arasında en 
kapsamlı yöntem olarak kabul edilir ve geleneksel refah ekonomisi teorisine dayanmaktadır (Rudmik ve Drummond, 2013). MFA'da bireysel yarar (yaşam süresi ve/veya yaşam kalitesinin artması gibi) öne çıkmaktadır. MFA'da hem yararlar hem de maliyetler parasal birimlerle ölçülmektedir. Alternatifler net yararına göre sıralanmakta ve en yüksek net yararı içeren uygulama seçilmektedir (Çalışkan, 2008). Yöntem doğru bir bakış açısı sunmasına karşın sağlık sektöründe bütün sonuçların parasal olarak ifade edilmesinin çok zor oluşu yöntemin uygulanabilirliğini güçleştirmektedir (Ağırbaş, 2014). Literatürde beklenen yararın ölçülmesinde iki farklı yaklaşım geliştirilmiştir. Yaklaşımlardan ilki beşeri sermaye (human capital) yaklaşımıdır ve beklenen yarar olarak bireyin gelecekteki gelirinin bugünkü değeri kullanılmaktadır. Beşeri sermaye yaklaşımı, yüksek gelirliler ile düşük gelirliler, çalışanlar ile çalışmayanlar arasında bir ayrımı içerdiği ve bireyin ölüm, hastalık ve yaralanma gibi sağlık risklerini gözetmediği için diğer yaklaşım olan ödeme istekliliği (willingness to pay) yaklaşımı geliştirilmiştir (Çalışkan, 2008). Ödemeye isteklilik yaklaşımı, bir bireyin mal veya hizmeti edinmek için veya olası bir kaybı önlemek için ödemeye istekli olduğu azami miktarı ifade etmektedir (Culyer, 2014, Akt: Bülüç, 2018).

\subsection{Maliyet Değer (Cost- Utility) Analizi (MDA)}

Literatür incelendiğinde maliyet değer analizinin, maliyet yararlanım analizi ve maliyet kullanım analizi olarak da adlandırıldığı görülmektedir. Günümüzde çağdaş tıp uygulamaları yalnızca yaşamın niceliğini değil, kalitesini de önemsemektedir. Bazı tedavi yöntemleri yaşam süresini uzatırken yaşam kalitesini olumsuz etkileyebilmektedir (Öksüz ve Malhan, 2005). MDA, yapılan tıbbi müdahalenin hastanın yaşam kalitesine etkisini de göz önüne almaktadır ve bu yönü ile maliyet etkililik analizinden farklılaşmaktadır. MDA'da maliyetler, müdahale sonucunda gerçekleşen sağlık statüsündeki iyileşmelerle karşılaştırılmaktadır. Sağlık statüsündeki kazanılan iyileşme QALY (quality adjusted life years - yaşam kalitesine ayarlanmış yıllar) ile ölçülmektedir (Drummond vd., 1987).

\subsubsection{QALY}

QALY, hastanın beklenen yaşam süresi ve bu yıllardaki yaşam kalitesi olarak tanımlanır (Rudmik ve Drummond, 2013). QALY değeri 1 ile 0 arasındadır. "1" mükemmel sağlı̆̆ temsil ederken " 0 " ise ölümü temsil etmektedir. Şekil 2 incelendiğinde hastaya müdahale edilir ise ölüm 1 senaryosunun gerçekleşmesi yerine hastanın A noktasındaki yaşam kalitesine sahip 
olacağ1 ve daha sonra B noktasına ulaştığında öleceği görülmektedir. Ölüm 1 ile Ölüm 2 arasında kalan açık renkli kısım ise QALY kazancını temsil etmektedir.

\section{Grafik 2. Müdahale sonucu kazanılan kaliteye ayarlanmış yaşam yılları}

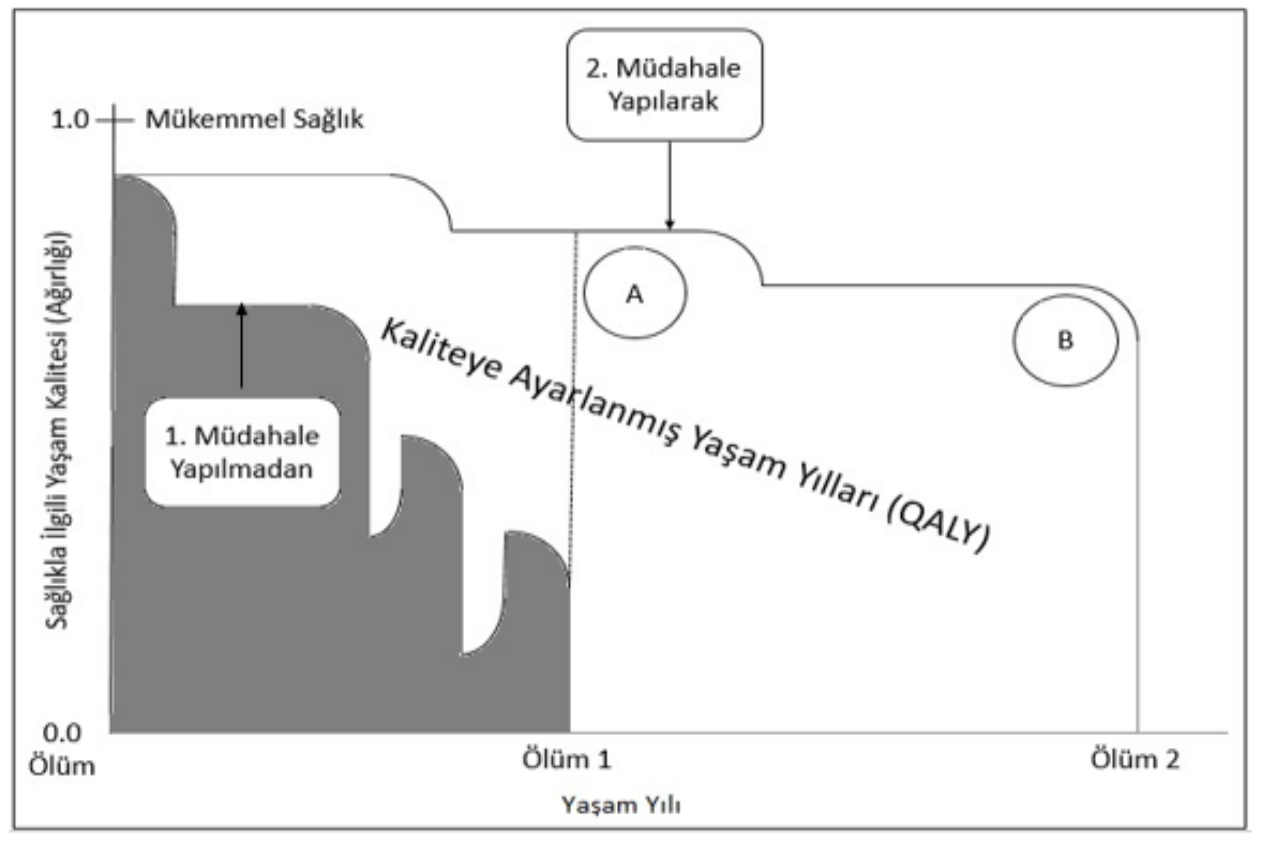

Kaynak: Rudmik ve Drummond, 2013.

MDA'da Maliyet/QALY formülü kullanılmakta ve alternatifler bu şekilde karşılaştırılmaktadır. Bu formül farklı çeşitlerdeki tüm müdahaleleri ortak bir birim haline getirdiği için farklı tür alternatiflerin karşılaştırmasında da kullanılabilmektedir. QALY ölçümünde genellikle kullanılan yaşam kalitesi araçları Short From-36, Nothingam sağlık profili, hastalık etki profili ve EQ-5D (European Quality of Life 5-Dimensions) anketidir (Çelik, 2013).

\subsection{Maliyet Etkililik (Cost - Effectiveness) Analizi (MEA)}

Maliyet etkililik analizi, sağlık sektöründe ekonomik değerlendirme yöntemlerinden en sık kullanılanıdır. MEA, sağlık hizmetinin girdileri (maliyetler) ile sağlık hizmeti çıktıları (faydaları) arasındaki ilişkiyi inceler. Bir başka ifade ile gereken sağlık bakımını en iyi kalitede minumum maliyet ile sunulmasını sağlayan bir analiz tekniğidir. MEA'da maliyetler parasal olarak ifade edilirken çıktı ise kazanılan yaşam süresi, kurtarılan yaşam, azaltılan hasta gün sayısı gibi doğal birimler ile değerlendirilmektedir (Ağırbaş, 2014; Balçık ve Şahin, 2013; Dewar, 2010; Drummond vd., 1987; Rudmik ve Drummond, 2013; Özgülbaş, 2014; 
Tengilimoğlu, 2018; Yiğit ve Erdem, 2014). MEA'nın dezavantajı olarak hastalıklar arasında karşılaştırma yapamaması gösterilebilir (Rudmik ve Drummond, 2013).

\subsection{1. İlave Maliyet Etkililik Oranı (IMEO)}

MEA'da alternatifler arasındaki karşılaştırmalar ilave maliyet etkililik oranı (incremental cost-effectiveness ratio -) ile yapılmalıdır. İMEO, yeni müdahale ile artan maliyetin etkililik durumundaki artan değişime bölünmesi ile elde edilir. İMEO, maliyet etkililik düzlemi üzerine yerleştirilerek alternatifler arasında karşılaştırma yapılır. (Rudmik ve Drummond, 2013).

\section{Grafik 3. Maliyet etkililik düzlemi}

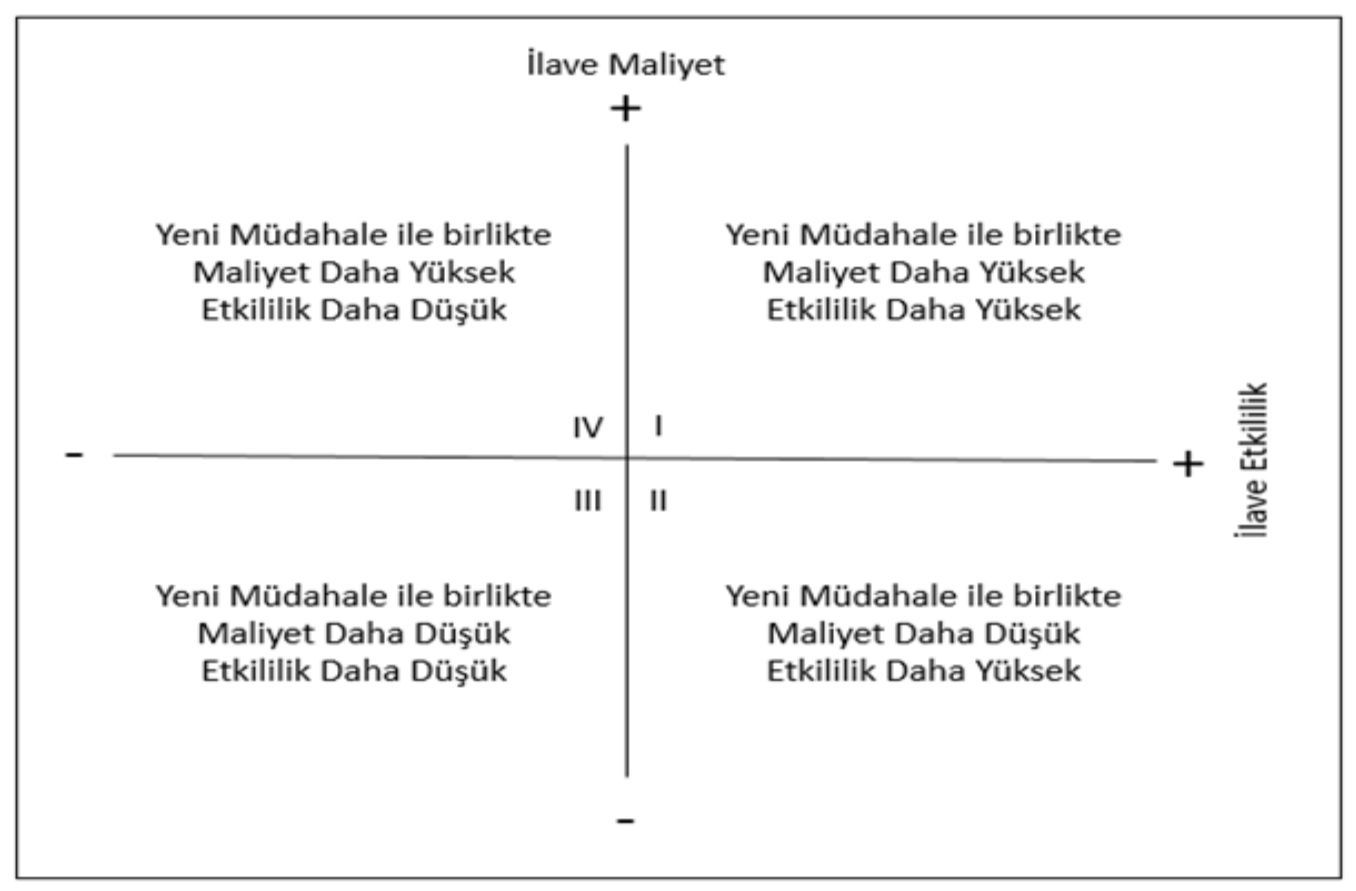

Kaynak: Rudmik ve Drummond, 2013

Grafik 3'te yer alan maliyet etkililik düzlemi, yeni bir tıbbi müdahalenin maliyet etkililik açısından kabul edilebilir sınırlar içerinde yer alıp almadığını belirlemede kullanılır. Düzlem üzerinde I. bölgedeki müdahalenin hem maliyeti hem de etkililiği daha yüksektir. II. bölgede müdahalenin maliyeti daha düşük ve etkililiği daha yüksektir. III. bölgede müdahalenin hem maliyeti hem de etkililiği daha düşüktür. IV. Bölgede ise maliyet daha yüksek iken etkililik daha düşüktür. Buna göre maliyetin daha düşük ve etkililiğin daha yüksek olduğu II. bölge kabul bölgesi olarak kabul edilmektedir (Rudmik ve Drummond, 2013). Hangi müdahalenin 
seçileceğini belirleme konusunda ise bir eşik değer belirlemek gerekmektedir. Dünya Sağlık Örgütü (DSÖ), kişi başına GSYİH'nin eşik değer olarak alınabileceği ve bir alternatifin maliyet etkili olup olmadığının şu şekilde belirlenebileceğini önermektedir (WHO, 2019b):

- İMEO kişi başına GSYİH’den düşük ise maliyet etkililiği yüksek,

- İMEO kişi başına GSYİH'nin 1-3 katı ise maliyet etkili,

- İMEO kişi başına GSYİH’nin 3 katından fazla ise maliyet etkili değil.

Tablo 2. Sağlık Hizmetlerinde Ekonomik Değerlendirme Özeti

\begin{tabular}{|c|c|c|c|c|}
\hline $\begin{array}{l}\text { Ekonomik } \\
\text { Değerlendirme } \\
\text { Yöntemi }\end{array}$ & $\begin{array}{l}\text { Girdilerin } \\
\text { Ölçümü } \\
\text { (Maliyet) }\end{array}$ & $\begin{array}{l}\text { Kazanım } \\
\text { Ölçümü }\end{array}$ & $\begin{array}{l}\text { Çıktıların } \\
\text { Ölçümü }\end{array}$ & $\begin{array}{l}\text { Sonuçların } \\
\text { Kullanımı }\end{array}$ \\
\hline $\begin{array}{l}\text { Maliyet- } \\
\text { Minimizasyon } \\
\text { Analizi (Cost } \\
\text { Minimization) }\end{array}$ & Parasal & Eşit sonuçlar & - & $\begin{array}{l}\text { Eşdeğer tedavi } \\
\text { yöntemleri içinde } \\
\text { düşük maliyetli } \\
\text { olanın seçimi }\end{array}$ \\
\hline $\begin{array}{l}\text { Maliyet-Fayda } \\
\text { Analizi (Cost } \\
\text { Benefit) }\end{array}$ & Parasal & $\begin{array}{l}\text { Parasal } \\
\text { Sonuçlar }\end{array}$ & Parasal Fayda & Maliyet/Fayda Oran 1 \\
\hline $\begin{array}{l}\text { Maliyet-Yaralanım } \\
\text { Analizi (Cost } \\
\text { Utility) }\end{array}$ & Parasal & Değersel & QALY, HYE & $\begin{array}{l}\text { QALY başına } \\
\text { maliyet }\end{array}$ \\
\hline $\begin{array}{l}\text { Maliyet-Etkililik } \\
\text { Analizi (Cost } \\
\text { Effectiveness) }\end{array}$ & Parasal & $\begin{array}{l}\text { Etkililik } \\
\text { Ölçümü }\end{array}$ & $\begin{array}{l}\text { Doğal Birimler } \\
\text { (kazanılan yaşam } \\
\text { süresi, kurtarılan } \\
\text { yaşam, azaltılan } \\
\text { hasta gün sayısı } \\
\text { vb.) }\end{array}$ & $\begin{array}{l}\text { Etkili Tedavi Vakası } \\
\text { Maliyeti: } \\
\text { (CT+CTSE- } \\
\text { CTE)/LY }\end{array}$ \\
\hline \multicolumn{5}{|c|}{$\begin{array}{l}\text { QALY (Quality Adjusted Life Years) : Kaliteye Ayarlı Yaşam Yılı } \\
\text { HYE (Healthy Years Equivalents) : Sağlıklı Geçen Yıllar Eşdeğeri }\end{array}$} \\
\hline
\end{tabular}


CT (Cost of Treatment) : Tedavi Maliyeti

CTSE (Cost of Treating Side Effects) : Yan Etkileri Tedavi Etmenin Maliyeti

CTE (Cost of Treating Events) : Hastalığı Düşük Seviyeye İndirilmesi ile Kazanılan Maliyetler

LY (Increase in number of Life Years) : Tedavinin Etkisiyle Kazanılan İlave Y1llar

Kaynak: Dewar, 2010: 121; Hoch and Dewa, 2005: 161; Kurtulmuş, 1998;76 Akt: Yiğit ve Erdem, 2014: 218; Yiğit ve Erdem, 2014: 218.

4. Sağlık Hizmetlerinde Ekonomik Değerlendirmeye Yönelik Yapılmış Akademik Çalışmalar

Sağlık hizmetlerinde ekonomik değerlendirme konulu çalışmalar özellikle belirli bir hizmetin maliyetine veya tedavi giderlerine odaklanılarak yapılmıştır. Mevcut çalışmalarda maliyet etkililik yöntemi en çok kullanılan teknik olarak ortaya çıkmaktadır.

Tablo 3. Sağlık Hizmetlerinde Ekonomik Değerlendirmeye Yönelik Yapılmış Akademik Çalışmalar

\begin{tabular}{|c|c|c|c|c|}
\hline YAZAR & YIL & KAYNAK & YÖNTEM & BULGULAR \\
\hline $\begin{array}{l}\text { YUMUŞAK } \\
\text { M. E. }\end{array}$ & 2008 & $\begin{array}{l}\text { YÖK Tez } \\
\text { Merkezi - } \\
220405\end{array}$ & $\begin{array}{l}\text { Diz osteoartritine yönelik } \\
\text { maliyet yarar analizi } \\
\text { Maliyet } \\
\text { EQ-5D Sağlık Anketi }\end{array}$ & $\begin{array}{l}\text { Osteoartrit } \\
\text { tedavisinin DSÖ } \\
\text { ölçeğine göre oldukça } \\
\text { maliyet yararlı } \\
\text { olduğu bulunmuştur. }\end{array}$ \\
\hline ÇETİN E. & 2011 & $\begin{array}{l}\text { YÖK Tez } \\
\text { Merkezi - } \\
297239\end{array}$ & $\begin{array}{l}\text { Sosyal Güvenlik kurumu } \\
\text { tarafından ödenen aile } \\
\text { planlaması yöntemleri olan; } \\
\text { OKS, RİA, enjeksiyon, } \\
\text { kondom, tüpligasyon ve } \\
\text { vazektominin maliyet etkililik } \\
\text { analizi }\end{array}$ & $\begin{array}{l}\text { Çalışmada } \\
\text { değerlendirilen altı } \\
\text { aile planlaması } \\
\text { yöntemi ve yöntem } \\
\text { kullanmama arasında } \\
\text { en maliyet-etkili }\end{array}$ \\
\hline
\end{tabular}




\begin{tabular}{|c|c|c|c|c|}
\hline & & & & $\begin{array}{l}\text { yöntemin RİA olduğu } \\
\text { bulunmuştur. }\end{array}$ \\
\hline BALÇIK P. Y. & 2013 & $\begin{array}{l}\text { YÖK Tez } \\
\text { Merkezi - } \\
339031\end{array}$ & $\begin{array}{l}\text { İleri evre küçük hücreli dışı } \\
\text { akciğer kanserinde } \\
\text { pemetrexed ve gemcitabine } \\
\text { tedavilerinin maliyet etkililik } \\
\text { analizi } \\
\text { Maliyet } \\
\text { EQ-5D Sağlık Anketi - } \\
\text { QALY }\end{array}$ & $\begin{array}{l}\text { İleri evre küçük } \\
\text { hücreli dışı akciğer } \\
\text { kanseri (KHDAK) } \\
\text { birinci basamak } \\
\text { tedavisinde } \\
\text { pemetrexed/cisplatin } \\
\text { tedavisi maliyet etkili } \\
\text { olarak bulunmamıştır. }\end{array}$ \\
\hline KAR A. & 2016 & $\begin{array}{l}\text { YÖK Tez } \\
\text { Merkezi - } \\
456823\end{array}$ & $\begin{array}{l}\text { Rüptüre olmamış serebral } \\
\text { anevrizmaların tedavisinde } \\
\text { cerrahi klipleme ve } \\
\text { endovasküler koil } \\
\text { yöntemlerinin maliyet } \\
\text { etkililik analizi } \\
\text { Maliyet } \\
\text { EQ-5D Sağlık Anketi - } \\
\text { QALY }\end{array}$ & $\begin{array}{l}\text { Endovasküler koil } \\
\text { yönteminin maliyet } \\
\text { etkili olduğu } \\
\text { bulunmuştur. }\end{array}$ \\
\hline TORUN N. & 2016 & $\begin{array}{l}\text { YÖK Tez } \\
\text { Merkezi - } \\
439329\end{array}$ & $\begin{array}{l}\text { Evde sağlık hizmetleri } \\
\text { kapsamında fototerapi } \\
\text { uygulamasına yönelik maliyet } \\
\text { etkililik analizi }\end{array}$ & $\begin{array}{l}\text { Evde fototerapi } \\
\text { uygulamasının } \\
\text { hastanedeki } \\
\text { uygulamalara göre } \\
\text { maliyet etkililik } \\
\text { açısından avantajlı } \\
\text { olduğu savunulabilir. }\end{array}$ \\
\hline
\end{tabular}




\begin{tabular}{|c|c|c|c|c|}
\hline BÜLÜÇ F. & 2018 & $\begin{array}{l}\text { YÖK Tez } \\
\text { Merkezi - } \\
518122\end{array}$ & $\begin{array}{l}\text { Koroner arter tedavisinde } \\
\text { kullanılan çıplak metal stent } \\
\text { ve ilaç salınımlı stentin } \\
\text { maliyet etkililik analizi } \\
\text { Maliyet } \\
\text { EQ 5D 5L Sağlık Anketi - } \\
\text { QALY }\end{array}$ & $\begin{array}{l}\text { İlaç salınımlı stent, } \\
\text { çıplak metal stente } \\
\text { göre çok maliyet } \\
\text { etkili bulunmuştur. }\end{array}$ \\
\hline
\end{tabular}

Tablo 3'te YÖK Tez Merkezi'nden ulaşılmış birkaç ekonomik değerlendirme çalışmalarının yazar, yıl, yöntem ve bulguları sunulmuştur. Çalışmaların ayrıntıları ise aşağıda sunulmuştur.

Yumuşak (2008) çalışmasında diz osteoartriti için maliyet yarar analizi yapmıştır. Müdahale öncesi yaşam kalitesi, EQ-5D UK tarifesine göre 0,31 QALYs olarak hesaplanmıştır ve literatür bilgilerine göre ortalama osteatrit için beklenen yaşam süresi olan 15 y1l ile çarpılmıştır. Müdahale öncesi kişinin fayda değeri 4,7 QALYs olarak hesaplanmıştır. Müdahale sonrası hastanın yaşam kalitesine ait bulguları tekrar UK tarifesi ağırlıkları üzerinden hesaplanarak 0,54 QALYs bulunmuştur ve ortalama bir osteatrit hastası için literatür bilgilerine göre beklenen yaşam süresi olan 15 yıl ile çarpılmıştır. Müdahale sonrası yaşam kalitesi 8,1 QALYs bulunmuştur. Buna göre müdahale sonrasında kazanılan ek etkililik 3,4 QALYS'dir. TC, Hastalık Yükü ve Maliyet Etkililik Projesinden alınan osteoartrit tedavi maliyeti 378,97\$'dir. Buna göre maliyet / QALYs 111.4 \$'dir. Fakat hasta perspektifinden maliyet değerlerine sosyal maliyetleri eklemek gerekmektedir. Hasta tedavi olma sürecinden işinden geri kalacak, tedavi için ulaşım ve başka maliyetlere katlanmak zorunda kalacaktır. Bu sosyal maliyetler ile birlikte hasta; maliyet /QALYs (sosyal maliyetler dahil) 120.8 \$ ödemek zorunda kalacaktır. Sonuç olarak osteoartrit yaşam süresinin artması ile toplumda sıklığı artan bir hastalık haline gelmiştir ve tedavisinin ise DSÖ’nün ölçeğine göre oldukça maliyet yararlı olduğu ileri sürülmüştür.

Çetin (2011) çalışmasında altı farklı aile planlaması yönteminin ve yöntem kullanmamanın maliyet etkililik analizini yapmıştır. "Çalışmada değerlendirilen altı aile planlaması yöntemi ve yöntem kullanmama arasında en maliyet-etkili yöntemin RİA (rahim içi 
araç) olduğu bulunmuştur. RİA'nın ardından en maliyet-etkili yöntemler sırası ile vazektomi ve tüpligasyon olarak bulunmuştur. İlave \%1'lik etkililik sağlanmak istendiğinde, vazektomi kullanılarak bu etkililik sağlanacak ise 480,15 TL, tüpligasyon ile sağlanacak ise 1821,87 TL ödenecek olduğu bulunmuştur. RİA'dan daha yüksek maliyetli ve daha az etkili girişimler olan OKS (kombine oral kontraseptifler), kondom, enjeksiyon ve yöntem kullanmamanın ret edilmesi gereken girişimler olduğunu bulunmuştur. Daha yüksek maliyet ve etkililiğe sahip olan vazektomi ve tüpligasyonun ise ödeyici kurumlar tarafından finanse edilip edilmeyeceğinin bu kurumların ödeme eşiklerine veya toplumun ödemeye gönüllügüne bağlı olduğu düşünülmüştür.

Balçık (2013) çalışmasında ileri evre küçük hücreli dışı akciğer kanserinde pemetrexed ve gemcitabine tedavilerinin maliyet etkililik analizini yapmıştır. İleri evre küçük hücreli dışı akciğer kanseri (KHDAK) birinci basamak tedavisinde pemetrexed/cisplatin tedavisi Türkiye sağlık sistemi üzerindeki yüksek bütçe etkisi ile maliyet etkili olarak bulunmamıştır. Çalışmanın sonuçlarına göre gemcitabine/cisplatin tedavisi alan bir hastanın yaşam boyu maliyeti 10.347,45 TL, pemetrexed/cisplatin tedavisi alan bir hastanın yaşam boyu maliyeti 17.783,34 TL bulunmuştur. Çalışmada, her iki tedavi alternatifinde de yaşam yılları 0,810 olarak bulunmuştur. Gemcitabine/cisplatin tedavisinin QALY değeri 0,532 iken, pemetrexed/cisplatin tedavisinde QALY 0,566 olarak bulunmuştur. İleri evre KHDAK birinci basamak pemetrexed/cisplatin tedavisi gemcitabine/cisplatin ile karşılaştırıldığında ilave 0,0337 QALY sağlamaktadır. İleri evre KHDAK birinci basamak pemetrexed/cisplatin tedavisinin ilave kazanılan QALY başına maliyeti 220.754 TL olarak bulunmuştur. Türkiye'de de resmi bir eşik değer bulunmadığından kişi başı GSYİH ölçüt olarak alındığında 220.754 TL olarak bulunan İMEO, eşik değerlerin çok üzerinde yer aldığından ileri evre KHDAK birinci basamak tedavisinde pemetrexed/cisplatin maliyet etkili olarak bulunmamıştır.

Kar (2016) çalışmasında rüptüre olmamış serebral anevrizmaların tedavisinde cerrahi klipleme ve endovasküler koil yöntemlerinin maliyet etkililik analizini yapmıştır. Koil yönteminin kazandırmış olduğu QALY 4,393 ve klipleme yönteminin kazandırdığ QALY 1,844 olarak bulunmuştur. Koil yönteminin yaşam boyu maliyeti 180.780,46 TL ve klipleme yöntemini yaşam boyu maliyeti 21.488,76 TL bulunmuştur. Cerrahi klipleme yönteminin QALY başına maliyeti 41.152,25 TL klipleme yönteminin QALY başına maliyeti ise 11.656,38 TL olarak bulunmuştur. Endovasküler koil tedavisi daha yüksek yaşam kalitesi sunmasına 
rağmen sahip olduğu yüksek maliyetten ötürü QALY başına maliyeti de yüksek çıkmaktadır. Ancak koil yönteminin maliyet etkili olup olmadığına karar vermek için eşik değerle karşılaştırılması yapılmıştır. Hesaplanan ilave maliyet etkililik oranı 62.481 bulunmuştur. Dolayısıyla eşik değer olarak kabul edilen 75.390 TL'nin altında bir değere sahip olduğu için endovasküler koil yönteminin maliyet etkili olduğu bulunmuştur.

Torun (2016) çalışmasında evde sağlık hizmetleri kapsamında fototerapi uygulamasına yönelik maliyet etkililik analizi yapmıştır. Çalışmadaki veriler neticesinde evde fototerapi uygulamasının hastanedeki uygulamalara göre daha az maliyetli olması, anne ve bebek arasındaki bağın kopmadığı bir ortamda yapılması, bebeklerin daha kısa sürede fototerapi alarak iyileşmesi, annelerin memnun kalması ve uygulama sırasında daha az kaygı yaşaması nedeniyle evde fototerapi uygulamasının maliyet-etkililik yönünden avantajlı, etkili ve güvenilir bir alternatif olduğu savunulmuştur.

Bülüç (2018) çalışmasında koroner arter tedavisinde kullanılan stentler olan çıplak metal stent (ÇMS) ve ilaç salınımlı stentlerin (ISS) maliyet etkililik analizini yapmıştır. Çalışma, da 190 hasta verisi incelenmiştir ve bu kapsamında hastalara EQ 5D 5L Sağlık Anketi uygulanmıştır. Elde edilen QALY değerleri karar ağacı analiziyle değerlendirilerek, ağırlıklandırılmış maliyet ve ağırlıklandırılmış QALY değerleri hesaplanmıştır. ÇMS'nin ağırlıklandırılmış maliyeti 2.340,71 TL ve İSS'nin ağırlıklandırılmış maliyeti 3.970,90 TL olarak hesaplanmıştır. ÇMS'nin ağırlıklandırılmış QALY değeri 0,8332 QALY ve İSS'nin ağırlıklandırılmış QALY değeri 0,8911 QALY bulunmuştur. Karar ağacıyla elde edilen ağırlıklandırılmış değerler ile İMEO kazanılan QALY başına 28.179,12 TL olarak hesaplanmıştır. İSS'nin ÇMS'ye göre maliyet etkili olup olmadığını değerlendirmek için maliyet etkililik düzlemine İMEO yerleştirilmiş ve ayrıca eşik değer belirlenerek sonuç değerlendirilmiştir. İMEO'nun eşik değer ve maliyet etkililik düzleminde aldığı noktadan hareketle; İSS'nin ÇMS'ye göre çok maliyet etkili olduğu sonucuna ulaşılmıştır.

\section{Sonuç}

Ekonomik değerlendirme, sağlık hizmetlerine ayrılan kaynakların daha verimli ve etkili kullanımı ile rasyonel kararlar alınabilmesi için oldukça önemlidir. Ekonomik değerlendirme yöntemleri, sağlık politika belirleyicilerine alternatiflerin hem maliyetini hem de sonuçlarını sunduğu için önemli karar destek araçlarındandır. Ekonomik değerlendirme teknikleri 
kullanılarak yapılacak maliyet hesaplarında sağl1k hizmeti sunumu için optimal kararların alınmasının sağlanacağı, güvenilir sonuçlar elde edilerek verimli sağlık hizmeti sunumunun gerçekleştirilecektir.

QALY başına maliyet birimi ile tüm hastalıklar, tedaviler, müdahaleler karşılaştırılabildiği için bu ortak birimin, sağlı hizmeti sunucuları ve geri ödeme kurumları tarafindan karar verme, önceliklendirme, sigorta tarafından karşılanma/karşılanmama gibi durumlarda kullanılmasının rasyonel kararlar sağlayacaktır.

Çalışmada tedavi giderlerini konu alan çalışmalara odaklanıldığı görülmüştür. Sadece belirli bir tedavi sürecindeki genellikle ilaç ve tıbbi malzeme giderlerini hesaplayan çalışmalar sınırlı çıktılar sunmaktadır. Ancak bir sağlık sorununun giderilmesine yönelik yapılan harcamalar ve/veya maliyet sadece sınırlı miktardaki tıbbi malzeme giderinden ibaret değildir. Daha kapsamlı sonuçlar elde edebilmek ve sağlık hizmetlerinin etkili ve verimli sunumunu, hatta makro düzeyde daha verimli planlanmasını sağlayacak maliyet verileri elde etmek için hastalık veya sağlık sorununun tüm yönleriyle ele alınıp maliyetlerinin, giderlerinin değerlendirilmesi yararlı olacaktır. Bunu sağlamak için hastalık maliyeti çalışmalarına odaklanmak, hastalık ve sağlı sorunlarının sosyal boyutuna dair maliyetleri de konu alan çalışmalar yapmak literatürü zenginleştirecektir. 


\section{Kaynaklar}

Ağırbaş, İ. (1999). Sağlık hizmetlerinde ekonomik değerlendirme teknikleri ve tcdd ankara hastanesinde prostat vakalarının incelenmesi yoluyla maliyet etkililik analizi uygulaması. Doktora tezi, Hacettepe Üniversitesi Sağlık Bilimleri Enstitüsü, Ankara.

Ağırbaş, İ. (2014). Sağlık Kurumlarında Finansal Yönetim ve Maliyet Analizi. Siyasal Kitabevi, Ankara.

Balçık P. Y. (2013). Türkiye'de ileri evre küçük hücreli dışı akciğer kanserinde pemetrexed ve gemcitabine tedavilerinin maliyet etkililik analizi. Doktora tezi, Hacettepe Üniversitesi Sosyal Bilimler Enstitüsü, Ankara.

Balçık P. Y., Şahin B. (2013). Sağlık hizmetlerinde maliyet etkililik analizi ve karar analizi. Hacettepe Sağllk İdaresi Dergisi 16 (2): 121-134.

Bülüç, F. (2018). Koroner arter hastalığı tedavisinde kullanılan stentlerin maliyet etkililik analizi. Yüksek lisans tezi, Ankara Üniversitesi Sağlık Bilimleri Enstitüsü, Ankara.

Culyer, A. (2014). The Dictionary of Health Economics. 3rd Ed., Edward Elgar Publishing Limited, Cheltenham. Aktaran: Bülüç, F. (2018). Koroner arter hastalığı tedavisinde kullanılan stentlerin maliyet etkililik analizi. Yüksek lisans tezi, Ankara Üniversitesi Sağlık Bilimleri Enstitüsü, Ankara.

Cunningham, S. J. (2001). An introduction to economic evaluation of health care. Journal of Orthodontics 28(3): 246-250.

Çalışkan, Z. (2008). Sağlık ekonomisi: kavramsal bir yaklaşım. Hacettepe Üniversitesi İktisadi ve İdari Bilimler Fakültesi Dergisi, 26(2): 29-50.

Çelik, Y. (2013). Sağlık Ekonomisi. Siyasal Kitabevi, Ankara.

Çetin, E. (2011). Türkiye'de aile planlaması yöntemlerinin maliyet-etkililik analizi. Yüksek lisans tezi, Hacettepe Üniversitesi, Sağlık Bilimleri Enstitüsü, Ankara.

Dewar D. M. (2010). Essentials of Health Economics. Jones and Bartlett Publishers, Canada.

Drummond M. F., Sculpher M. J., Claxton K., Stoddart G. L., Torrance G. W. (1987) Methods for Economic Evaluation of Health Care Programmes. Oxford University Press, Oxford.

Drummond, M. F., Aguiar-Ibáñez, R., Nixon, J. (2006). Economic evaluation. Singapore Med $J$ 47(6): 456.

Hoch, J.S., Dewa,C.S. (2005). Introduction To Economic Evaluation: What's in A Name? J Psychiatry, Vol 50, No 3, March. 
Kar A. (2016). Rüptüre olmamış serebral anevrizmaların tedavisinde cerrahi klipleme ve endovasküler koil yöntemlerinin maliyet etkililiğinin değerlendirilmesi. Doktora tezi, Hacettepe Üniversitesi Sosyal Bilimler Enstitüsü, Ankara.

Kurtulmuş, S. (1998). Sağlık Ekonomisi Ve Hastane Yönetimi, Timaş Yayınları, İstanbul. Aktaran: Vahit Y., Erdem R. (2014). Sağlık hizmetlerinde maliyet etkililik analizi. Süleyman Demirel Üniversitesi İktisadi ve İdari Bilimler Fakültesi Dergisi 19 (2): 211 236.

OECD (2019a). OECD Health Statistics 2018. Erişim Adresi: [http://dx.doi.org/10.1787/888933835345] Erişim Tarihi: 04.07.2019.

OECD (2019b). OECD Health Statistics 2018. Erişim Adresi: [http://dx.doi.org/10.1787/888933835383] Erişim Tarihi: 04.07.2019.

Öksüz, E., Malhan, S. (2005). Sağlı̆̆a bağlı yaşam kalitesi: kalitemetri, Başkent Üniversitesi Yayınları, Ankara.

Özgülbaş, N. (2014). Sağlık Sektöründe Hizmet ve Hastalık Maliyet Analizi. Siyasal Kitabevi, Ankara.

Rudmik, L., Drummond, M. (2013). Health economic evaluation: important principles and methodology. Laryngoscope, 123:1341-1347.

Tengilimoğlu, D., Akbolat, M., Işık, O. (2018). Sağlık İşletmeleri Yönetimi. Nobel Akademik Yayıncılık, Ankara.

Tengilimoğlu, D. (2018). Sağlık Politikası. Nobel Akademik Yayıncılık, Ankara.

Torun N. (2016a). Evde Sağlık Hizmetleri Kapsamında Fototerapi Uygulamasına Yönelik Maliyet Etkililik Analizi Ankara İli Örneği. Doktora Tezi, Gazi Üniversitesi, Sosyal Bilimler Enstitüsü, Ankara.

Torun, N. (2016b). Evde Bakım Hizmetlerine Yönelik Yapılan Maliyet Etkililik Çalışmalarına Genel Bir Bakış, Uluslararası Sağlık Yönetimi Ve Stratejileri Araştırma Dergisi, 2(2), $12-23$.

Torun, N., (2017). Ankara İlinde Evde Fototerapi Uygulamasının Maliyet Etkililik Analizi: Maliyet Etkililik Düzlemi ve Grafiğgi Açısından Değerlendirme, Hacettepe Sağlık İdaresi Dergisi, 2017; 20(2): 219-246.

TÜİK (2019). TÜİK Sağlık Harcamaları İstatistikleri. Erişim Adresi: [http://www.tuik.gov.tr/UstMenu.do?metod=temelist] Erişim Tarihi: 25.06.2019.

Vahit Y., Erdem R. (2014). Sağlik hizmetlerinde maliyet etkililik analizi. Süleyman Demirel Üniversitesi Iktisadi ve İdari Bilimler Fakültesi Dergisi 19 (2): 211-236. 
Višnjić, A., Veličković, V., Milosavljević, N. S., (2011). QALY - measure of cost-benefit analysis of health interventions. Scientific Journal of the Faculty of Medicine, 28(4): 195-199.

Walter, E., Zehetmayr, S. (2006). Guidelines on health economic evaluation. Consensus Paper, Institut für Pharmaökonomische Forschung.

WHO (2019a). Health technology assessment. Erişim Adresi: [https://www.who.int/healthtechnology-assessment/en/] Erişim Tarihi: 20.07.2019.

WHO (2019b). Thresholds for the cost-effectiveness of interventions: alternative approaches. Erişim Adresi: [https://www.who.int/bulletin/volumes/93/2/14-138206/en/] Erişim Tarihi: 24.07.2019.

Yumuşak, M. E. (2008). Diz osteoartriti için maliyet yarar analizi. Yüksek lisans tezi, Başkent Üniversitesi, Sosyal Bilimler Enstitüsü, Ankara. 